\title{
Multivessel coronary artery disease: A key predictor of short-term prognosis after reperfusion therapy for acute myocardial infarction
}

Results of recent studies have suggested that routine cardiac catheterization may be unnecessary after reperfusion therapy for acute myocardial infarction. Therefore to better define the short-term prognostic value of early coronary angiography, and specifically the prognostic significance of multivessel coronary artery disease, the angiographic findings of $\mathbf{8 5 5}$ patients consecutively enrolled in five phases of the TAMI study were correlated with their in-hospital outcome. All patients received intravenous thrombolytic therapy (tissue plasminogen activator, urokinase, or both agents) and underwent cardiac catheterization within 90 minutes of the initiation of therapy. Multivessel disease, defined as the presence of $\geq 75 \%$ luminal diameter stenosis in two or more major epicardial arteries, was documented in 236 patients. When compared with the group of patients without multivessel disease, this group had a higher prevalence of coronary risk factors and more frequently had a history of antecedent ischemic chest pain. Although the severity of the infarct zone dysfunction was similar in the two groups $(-2.77 \pm 1.00$ vs $-2.50 \pm 1.09 \mathrm{SD} / \mathrm{chord}, p=\mathrm{NS})$, global left ventricular ejection fraction was lower in the group with multivessel disease (48.6 $\pm 12.4 \%$ vs $51.8 \pm 10.6 \%, p<0.01)$. This was associated with a significant difference in the function of the noninfarct zone. Whereas this region was hyperkinetic in the group with minimal or single-vessel disease, it was hypocontractile or dyskinetic in those with multivessel disease $(+0.66 \pm 1.53$ vs $-0.52 \pm 1.73 \mathrm{SD} / \mathrm{chord}$, $p=0.0001$ ). The in-hospital mortality rate, predominantly the result of myocardial failure and cardiogenic shock, was also significantly higher in the multivessel group $(11.4 \%$ vs $4.2 \%$, $p<0.0001$ ). By means of data from the 708 patients enrolled in the first three TAMI studies, a statistical model was developed to describe the determinants of in-hospital survival. By logistic regression analysis the strongest independent predictor of in-hospital mortality was the number of diseased vessels $(p<0.002)$. Other parameters that contributed significantly included global left ventricular ejection fraction $(p=0.01)$, TIMI grade infarct vessel flow $(p=0.03$ ), and patient age $(p=0.03)$. According to this model the prognostic significance of one additional year of age was equivalent to a reduction in left ventricular function of 1.1 ejection fraction percentage points; one additional diseased vessel was equivalent to 15 additional years of age or a reduction in ejection fraction of 16 percentage points. These data suggest that more aggressive revascularization procedures should be considered in the early postinfarction period for patients with multivessel disease and noninfarct zone dysfunction. In the absence of reliable noninvasive techniques, coronary angiography remains the procedure of choice for identifying this high-risk subgroup. (AM HEART J 1991;121:1042.)

David W. M. Muller, MBBS, FRACP, Eric J. Topol, MD, Stephen G. Ellis, MD, Kristina N. Sigmon, MA, Kerry Lee, PhD, Robert M. Califf, MD, and the Thrombolysis and Angioplasty in Myocardial Infarction (TAMI) Study Group. Ann Arbor, Mich., and Durham, N.C.

From the Division of Cardiology, Department of Internal Medicine, University of Michigan Medical Center; and the Division of Cardiology, Duke University Medical Center.

Received for publication Aug. 14, 1990; accepted Sept. 20, 1990.

Reprint requests: Eric J. Topol, MD, Division of Cardiology, University of Michigan Medical Center, B1 F245, 1500 E. Medical Center Dr., Ann Arbor, MI 48109-0022.

$4 / 1 / 27166$
In selected patients early administration of intravenous thrombolytic therapy has become an integral component of the management of acute myocardial infarction and has been shown to augment recovery of left ventricular function ${ }^{1-3}$ and to improve both short-term and long-term postinfarction survival. ${ }^{4-6}$ In the prethrombolytic era the most consistent pre- 
dictor of survival after myocardial infarction was global left ventricular ejection fraction. ${ }^{7}$ Although this remains an important determinant of postinfarction survival, the relatively modest impact of reperfusion therapy on left ventricular function appears to correlate poorly with its effect on subsequent mortality. ${ }^{8}$ This suggests that left ventricular functional recovery is an insensitive predictor of survival after reperfusion therapy. Other clinical and angiographic parameters may be more reliable prognostic determinants. We have recently reported a strong correlation between in-hospital mortality after thrombolytic therapy and the functional integrity of the noninfarct zone. ${ }^{9}$ The present study of a large group of patients receiving thrombolytic therapy for acute myocardial infarction was undertaken first to evaluate the contribution of the extent of coronary artery disease to short-term prognosis and second to develop a statistical model, based on clinical and angiographically derived variables, for describing the determinants of short-term postinfarction survival.

\section{METHODS}

Patient selection. The study population consisted of 855 patients consecutively enrolled in five phases of the multicenter Thrombolysis and Angioplasty in Myocardial Infarction (TAMI) study from January 1985. Data from these patients were collected prospectively and entered into a computerized Duke University data base for subsequent analysis. The study protocol was similar for each of the five phases of the study. ${ }^{10}$ Briefly all patients first seen within 4 hours of the onset of symptoms of acute myocardial infarction with associated ST segment elevation of $>0.1 \mathrm{mV}$ in two or more contiguous ECG leads were eligible for enrollment. In addition, patients first seen within 6 hours who had continuing ischemic chest pain were considered eligible. Exclusion criteria included age $>75$ years, prior coronary artery bypass graft surgery, prior $\mathrm{Q}$ wave infarction in the same myocardial territory as the index event, contraindications to thrombolytic therapy, and the presence of cardiogenic shock, defined as systolic blood pressure $<85 \mathrm{~mm} \mathrm{Hg}$ despite an adequate left ventricular filling pressure (pulmonary capillary wedge pressure $>18$ $\mathrm{mm} \mathrm{Hg}$ ). The study protocols were approved by the investigational review board of each participating institution and informed consent was obtained from all patients before they were enrolled in the study.

Treatment regimen. In each phase one or more thrombolytic agents were administered intravenously as soon as possible after enrollment. The thrombolytic regimen included recombinant tissue-type plasminogen activator in four of the five phases. This agent was given alone or in combination with intravenous urokinase, prostacyclin, or heparin. The remaining group received high-dose urokinase monotherapy. Patency of the infarct-related artery was determined by selective coronary angiography $90 \mathrm{~min}$ utes after the initiation of the thrombolytic infusion. Those patients with TIMI grade 2 or 3 flow in the infarct-related artery and suitable coronary anatomy were randomly assigned in the first phase of the TAMI study to either immediate coronary angioplasty or to deferred angioplasty, performed 7 to 10 days after they were seen. In the remaining studies coronary angioplasty was deferred until the time of predischarge angiography in all patients with patent infarct vessels. Dilatation of noninfarct vessels was not attempted at the time of the initial or the follow-up procedure. When considered necessary, angioplasty of these remote zone vessels was performed at a subsequent staged procedure. Those patients in whom the infarct vessel remained occluded at the time of the 90-minute angiogram (TIMI grade 0 or 1 coronary flow) were considered for "rescue" angioplasty in all phases of the study. Successful coronary angioplasty was defined as TIMI grade 2 or 3 flow in the infarct vessel and a reduction in severity of the stenosis to less than $50 \%$ of the cross-sectional diameter determined by quantitative angiographic measurement. Repeat coronary angiography and contrast ventriculography were performed before hospital discharge to evaluate infarct vessel patency and changes in global and regional left ventricular function. Intercurrent angiography was also performed for symptoms of recurrent myocardial ischemia or hemodynamic compromise.

Cardiac catheterization. Contrast left ventriculography was performed in the 30-degree right anterior oblique projection. Global left ventricular ejection fraction was determined by means of the area-length method. ${ }^{11}$ Analysis of infarct and noninfarct zone regional wall motion was performed by means of the center-line chord method..$^{12}$ Enddiastolic and end-systolic frames were selected for analysis by an experienced observer, blinded to the treatment regimen, at the University of Michigan angiographic core laboratory. Selective coronary angiography was performed in multiple projections, and the severity of coronary artery stenoses was measured by means of a previously validated, computerized edge-detection algorithm. ${ }^{113}$ Multivessel disease was defined for the purposes of the study as the presence of stenoses $\geq 75 \%$ of the coronary luminal diameter in more than one of the three major epicardial vessels. Left main disease was considered to be equivalent to disease affecting both the left anterior descending and circumflex coronary arteries. For comparison the data were also analyzed by means of a 50 : luminal diameter stenosis criterion.

Clinical outcomes. The end points evaluated were in-hospital mortality, infarct vessel reocclusion, reinfarction, the need for surgical revascularization, and global and regional left ventricular function. In-hospital death included any death occurring before the patient was discharged from the hospital regardless of the cause. Infarct vessel reocclusion was defined as the angiographically documented reocclusion (TIMI grade 0 or 1 flow) of a previously patent infarct-related artery any time before the patient was discharged from the hospital. Reinfarction was defined as the occurrence of recurrent ischemic chest pain associated with a resulting increase in cardiac enzyme levels during the hospital course. Coronary artery bypass graft 
Table I. Baseline clinical characteristics

\begin{tabular}{lcc}
\hline \multicolumn{1}{c}{ Characteristics } & $\begin{array}{c}\text { No multivessel } \\
\text { disease } \\
(n=619)\end{array}$ & $\begin{array}{c}\text { Multivessel } \\
\text { disease } \\
(n=236)\end{array}$ \\
\hline Male (\%) & 79 & 82 \\
Age (yrs) & $55 \pm 10$ & $58 \pm 10$ \\
Coronary risk factors $(\%)$ & 39 & \\
$\quad$ Systemic hypertension & 12 & 48 \\
$\quad$ Diabetes mellitus & 13 & 11 \\
$\quad$ Hyperlipidemia & & \\
Prior medical therapy $(\%)$ & 12 & 18 \\
$\quad$ Beta blockers & 6 & 18 \\
$\quad$ Calcium channel blockers & 23 & 21 \\
$\quad$ Aspirin & 12 & 19 \\
$\quad$ Diuretics & & \\
Infarct location $(\%)$ & 42 & 36 \\
$\quad$ Anterior & 57 & 63 \\
$\quad$ Inferior & 1 & 1 \\
$\quad$ Other & 7 & 29 \\
Prior myocardial infarction $(\%)$ & $176 \pm 68$ & $178 \pm 68$ \\
Time to lytic therapy (min) & & \\
\hline
\end{tabular}

surgery was considered to be an emergency procedure if the patient required direct transfer from the cardiac catheterization laboratory to the operating room, an urgent procedure if it was performed during the hospital course for recurrent myocardial ischemia, and elective if performed subsequently.

Statistics. All values are quoted as mean \pm one standard deviation or median (twenty-fifth, seventy-fifth percentiles) unless otherwise stated. Selected clinical variables were compared by means of the Wilcoxon rank-sum test for nonparametric variables and the chi-square test for discrete variables. Changes in global and regional left ventricular function were compared by means of the Wilcoxon rank-sum test. A two-tailed probability of less than 0.05 was considered significant. Data from the 708 patients enrolled in TAMI studies 1 to 3 were used to develop a stepwise logistic regression model describing the contribution of a number of clinical and angiographic variables to the observed in-hospital mortality. For this model missing left ventricular ejection fraction data were imputed by means of available baseline characteristics.

\section{RESULTS}

Patient characteristics. According to the $75 \%$ luminal diameter stenosis criterion, multivessel coronary artery disease was present in $236(27.6 \%)$ of the 855 patients forming the study population. The baseline angiographic findings and demographic composition of the group of patients with single-vessel disease and those with multivessel disease are summarized in Table I. The mean age and sex distribution were similar in the two groups. A history of antecedent ischemic chest pain was obtained in $60.4 \%$ of the group with multivessel disease and $48.9 \%$ of the group with
Table II. Initial angiography

\begin{tabular}{lcc}
\hline & $\begin{array}{c}\text { No multivessel } \\
\text { disease } \\
(n=619)\end{array}$ & $\begin{array}{c}\text { Multivessel } \\
\text { disease } \\
(n=236)\end{array}$ \\
\hline Infarct-related artery $(\%)$ & & \\
Left anterior descending & 41 & 34 \\
Left circumflex & 10 & 17 \\
Right coronary artery & 48 & 46 \\
Saphenous vein graft & 0.5 & 2 \\
Left main coronary artery & 0.5 & 1 \\
TIMI flow grade (90 min) $(\%)$ & & \\
0-1 & 30 & 36 \\
2-3 & 70 & 64 \\
Acute PTCA (\%) & 43 & 37 \\
PTCA success $(\%)$ & 79 & 74 \\
Final acute patency $(\%)$ & 94 & 86 \\
\hline
\end{tabular}

PTCA, percutaneous transluminal coronary angioplasty.

single-vessel disease. Hypertension, diabetes, and peripheral vascular disease tended to be more prevalent and the prior use of beta-adrenergic-and calcium channel-blocking agents higher in the group with multivessel disease (Table I). The prevalence of the use of aspirin, on the other hand, was similar in the two groups $(21.4 \%$ vs $23.2 \%)$.

Angiographic findings. The distribution of infarct territories was similar in the two groups of patients (Table I). The left anterior descending artery was the infarct-related artery in $34.3 \%$ of the group with multivessel disease (group 1) compared with $40.8 \%$ of those patients without multivessel disease (group 2). The right coronary artery was the culprit vessel in $46.4 \%$ and $47.5 \%$, respectively, and the left main coronary artery was identified as the infarct-related artery in one patient in each group (Table II). The infarct vessel was patent (TIMI grade 2 or 3 flow) 90 minutes after the initiation of the thrombolytic therapy in $63.7 \%$ of patients in group 1 and $70.4 \%$ of those in group 2. Time to initiation of therapy from the onset of chest pain was similar in the two groups (178 vs 176 minutes). The residual stenosis at the final diagnostic coronary angiogram was not recorded for the 386 patients in the initial phase of the study. In the subsequent phases mean residual coronary stenosis was $91.6 \%$ in patients in group 1 compared with $85.1 \%$ in group 2 . Coronary angioplasty was performed acutely in $37.3 \%$ of the patients with multivessel disease and $43.4 \%$ of those without multivessel disease and successfully reduced the infarct vessel stenosis to $<50 \%$ luminal diameter in $78.9 \%$ and $78.6 \%$ of these attempts, respectively.

Technically adequate contrast left ventriculograms 


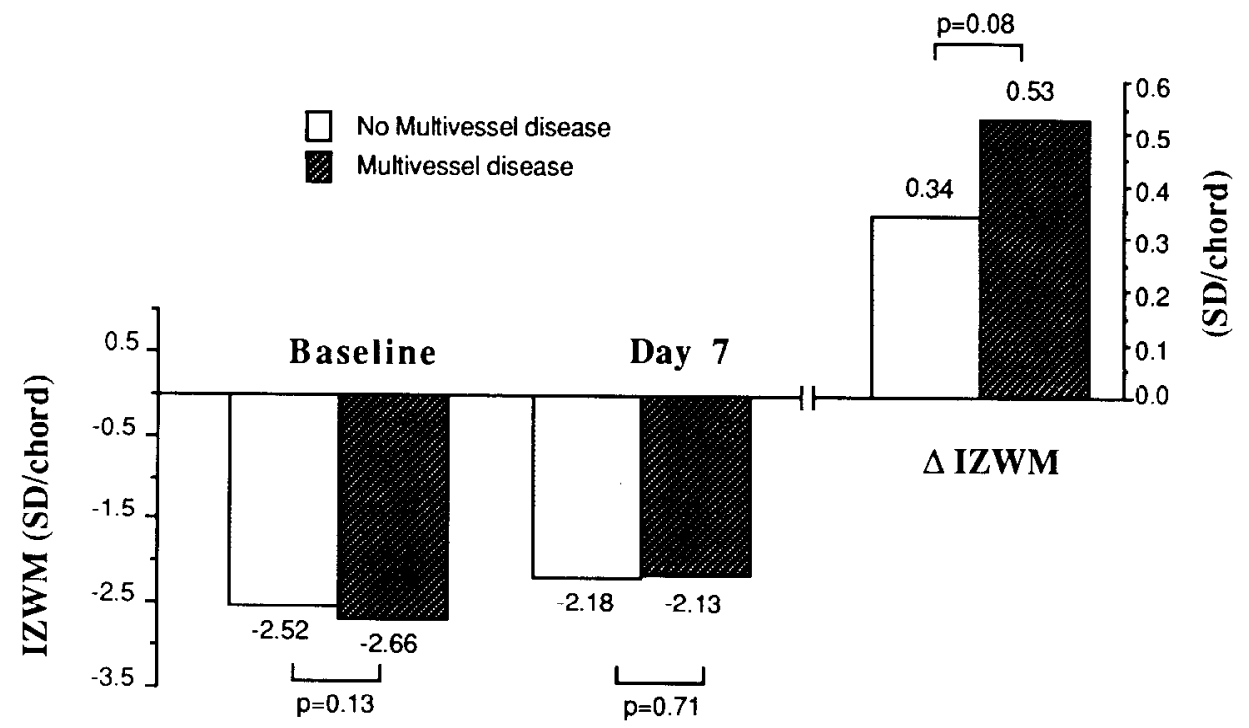

Fig. 1. Acute and convalescent infarct zone wall motion (IZWM) in patients with and without multivessel disease (paired data). 'There was no significant difference between the two groups. $S D$, standard deviation from normal mean.

were available for analysis in 745 patients when they were first seen and 628 patients at follow-up catheterization before they were discharged from the hospital. Global left ventricular ejection fraction was relatively well preserved acutely in both groups but was lower in the group with multivessel disease than in those without multivessel disease $(47.6 \pm 12.4 \%$ vs $51.5 \pm 10.9 \%, p<0.01)$. The severity of the regional wall motion abnormality in the infarct zone was similar in the two groups $(-2.77 \pm 1.00$ vs $-2.50 \pm 1.09 \mathrm{SD} /$ chord, $p=0.13$ ). In contrast; although heterogeneous in both populations (ranging from -3.92 to $+5.14 \mathrm{SD} /$ chord), the median function of the noninfarct zone was significantly different between the two groups. The group with minimal or single-vessel disease more frequently demonstrated augmented function of this region (twenty-fifth, fiftieth, and seventy-fifth percentiles: $-0.21,+0.69$, and $+1.58 \mathrm{SD} /$ chord), whereas those with multivessel disease more commonly had impaired noninfarct zone function at the time of the acute contrast left ventriculogram $(-1.85,-0.38$, and $+0.70 \mathrm{SD} /$ chord, $p<0.0001)$. Analysis of 583 paired baseline and predischarge left ventriculograms showed that regional wall motion of the infarct zone improved to a similar degree in the two groups (Fig. 1). The improvement in global ejection fraction, on the other hand, was greater in the patients with multivessel disease, but the difference did not reach statistical significance $(1.93 \pm 9.0$ vs $0.34 \pm 9.0 \%, p=0.07)$ (Fig. 2). This apparently greater improvement in ejection fraction was associated with a reduction in the severity of remote zone dysfunction in the group with multivessel disease compared with regression of the augmented function of this region in the group without multivessel disease $(+0.035 \pm 1.11$ vs $-0.18 \pm 1.22 \mathrm{SD} /$ chord, $p=0.02$ ) (Fig. 3).

Hospital course. The presence of multivessel coronary artery disease was clearly associated with a relatively poor in-hospital prognosis. Although infarct vessel reocclusion occurred somewhat more frequently in the group without multivessel disease $(14 \%$ vs $9 \%)$, the in-hospital mortality rate was significantly higher in the group with two- or three-vessel coronary artery disease $(11 \%$ vs $4 \%, p<0.0001)$ (Table III). The predominant cause of death in this group was myocardial failure and cardiogenic shock, and the median was 4 days (Table IV). Both emergency and elective coronary artery bypass graft surgery were performed more frequently in the group with multivessel coronary disease $(10 \%$ vs $4 \%$ and $21 \%$ vs $4 \%$, respectively). The clinical and angiographic variables that predicted in-hospital mortality by univariate analysis are shown in Table V. Of the variables examined by multiple logistic regression analysis, the strongest predictor of in-hospital mortality was the number of diseased vessels $(p=0.002)$ (Table VI). Global left ventricular ejection fraction $(p=0.01)$, TIMI grade infarct vessel flow $(p=0.03)$, and patient age $(p=0.03)$ also contributed significantly (Table VI). With this model the prognostic significance of one additional year of age 


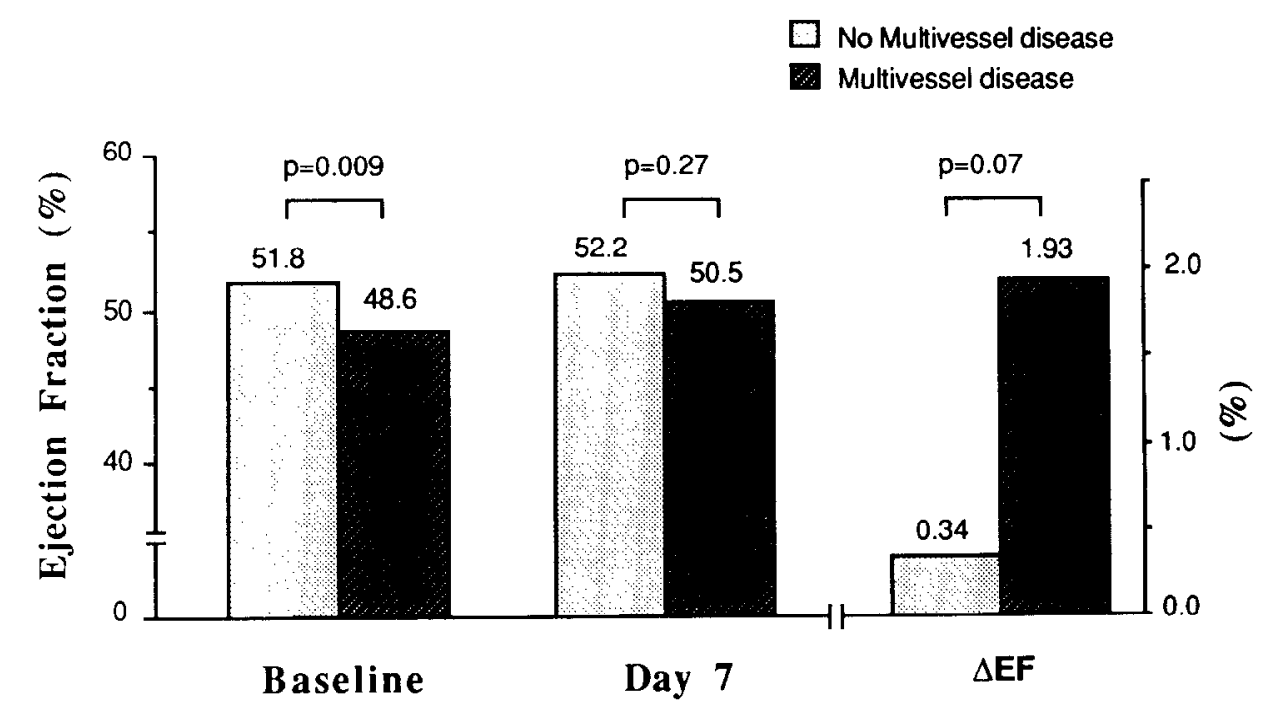

Fig. 2. Acute and convalescent left ventricular ejection fraction (paired data). Global left ventricular function was poorer in patients with multivessel disease but improved to a greater extent than in those without multivessel disease.

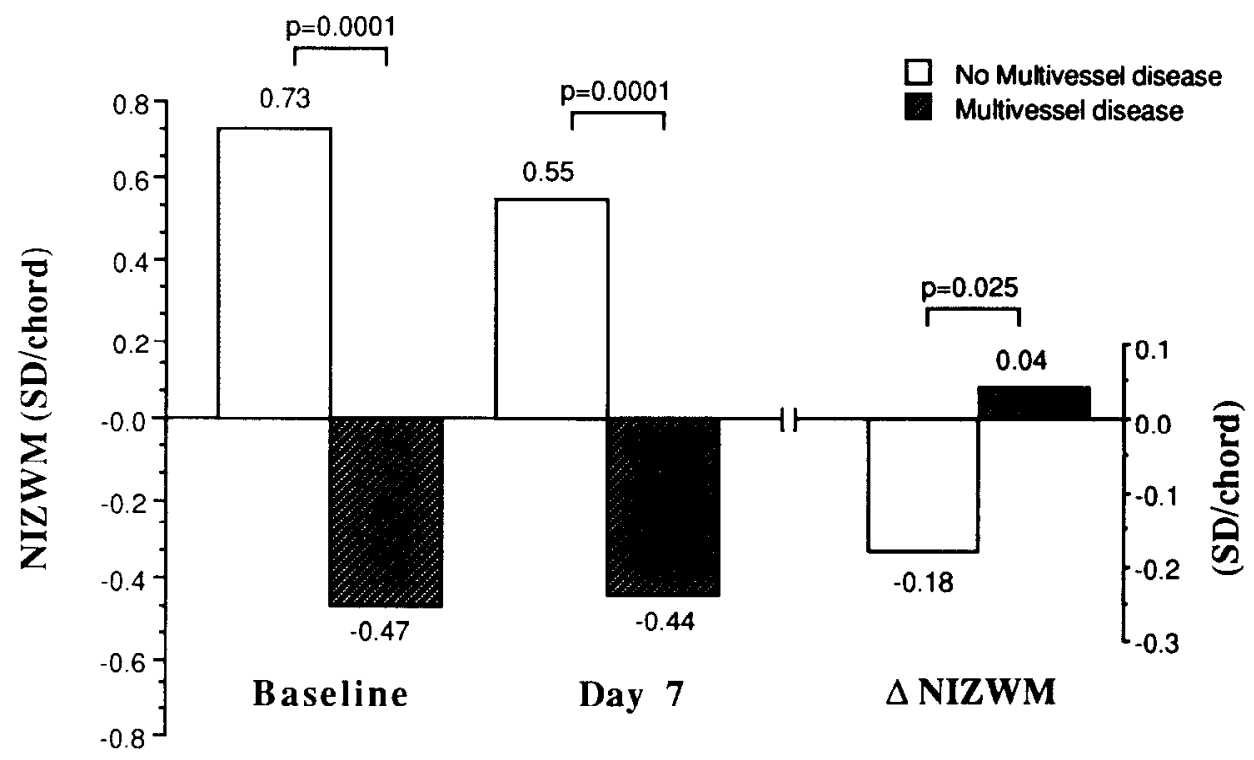

Fig. 3. Acute and convalescent noninfarct zone wall motion (NIZWM) (paired data). Positive values denote hyperkinesis; negative values denote hypokinesis.

was equivalent to a reduction in left ventricular ejection fraction of 1.1 percentage points. One additional diseased vessel was of equivalent prognostic significance to 15 additional years of age or a reduction in ejection fraction of 16 percentage points, and the presence of 'IIMI grade 0 flow in the infarct-related artery was equivalent prognostically to 1.6 additional diseased vessels, 23 additional years of age, or a reduction in ejection fraction of 25 percentage points.

With the use of the less stringent criterion for multivessel disease of more than $50 \%$ diameter stenosis in more than one major epicardial vessel, the overall results of this study change to only a small extent. According to this definition multivessel disease was present in $46 \%$ of the total population. Acute left ventricular ejection fraction was $49.9 \%$ in the group with multivessel disease compared with $52.1 \%$ in those without multivessel disease, and noninfarct zone function was $-0.16 \pm 1.76 \mathrm{SD} /$ chord and $+0.85 \pm 1.51 \mathrm{SD} /$ chord, respectively. The most 
important predictor of in-hospital mortality by logistic regression analysis remained the presence of multivessel coronary artery disease.

\section{DISCUSSION}

The principal finding of this study was that, of a large number of clinical and angiographic variables, the strongest predictor of in-hospital mortality after reperfusion therapy for acute myocardial infarction was the presence of multivessel coronary artery disease. This was true whether multivessel disease was defined as the presence of $50 \%$ or $75 \%$ stenoses in the noninfarct vessels. Multivessel disease has long been recognized as an important predictor of long-term survival both in patients with chronic stable angina ${ }^{14,15}$ and in those treated conventionally after acute myocardial infarction. ${ }^{16,17}$ The impact of the extent of coronary artery disease on the short-term mortality of acute myocardial infarction has, on the other hand, been less extensively evaluated, particularly in patients treated with reperfusion therapy. Echocardiographic evidence of dysfunction of the noninfarct zone ${ }^{18}$ and ECG changes of "ischemia at a distance"17, 19-20 have been previously correlated with increased short-term mortality. These studies have inferred but have not angiographically demonstrated the presence and importance of significant noninfarct vessel stenoses.

Multivessel disease and noninfarct zone function. In this study acute noninfarct zone function, a significant prognostic factor by univariate analysis, was heterogeneous in both groups of patients, ranging from markedly hyperkinetic to markedly hypokinetic. Similar findings have been reported in other clinical studies. ${ }^{18,21}$ Follow-up cardiac catheterization showed regression of the hypercontractile response in those without multivessel disease. This may have been due to the combined effects of a reduction in circulating endogenous catecholamines, to changes in diastolic function of the infarct zone, and to a simple statistical regression toward the normal mean. In contrast the function of the noninfarct zone tended to improve with time in the group with multivessel disease. The relationship between the extent of coronary artery disease, coronary blood flow, and regional myocardial function has been investigated in both clinical and animal studies. Stamm et al. ${ }^{21}$ performed resting two-dimensional echocardiography on 30 patients with acute myocardial infarction at a mean of 10.8 hours from the onset of symptoms. Asynergy of the remote, noninfarct zone was present in $77 \%$ of those patients with multivessel disease (defined as the presence of $\geq 70 \%$ stenosis of more than one epicardial coronary artery) compared with
Table III. In-hospital clinical and angiographic outcome

\begin{tabular}{lcc}
\hline & $\begin{array}{c}\text { No multivessel } \\
\text { disease } \\
(n=619)\end{array}$ & $\begin{array}{c}\text { Multivessel } \\
\text { disease } \\
(n=236)\end{array}$ \\
\hline Reocclusion $(\sigma)$ & 14 & 9 \\
Reinfarction $(\sigma)$ & 3 & 3 \\
Coronary artery & & \\
$\quad$ bypass surgery $(\%)$ & 4 & 10 \\
Emergency & 3 & 11 \\
Urgent & 7 & 21 \\
$\quad$ Elective & 4 & 11 \\
Death $(\%) *$ & &
\end{tabular}

${ }^{*} p<0.0001$.

Table IV. In-hospital mortality: Causes and timing

\begin{tabular}{lcc}
\hline & $\begin{array}{c}\text { No multivessel } \\
\text { disease } \\
(n=26)\end{array}$ & $\begin{array}{c}\text { Multivessel } \\
\text { disease } \\
(n=27)\end{array}$ \\
\hline Cause of death $(\%)$ & & \\
Reinfarction & 15 & 27 \\
Cardiogenic shock & 69 & 38 \\
Arrhythmia & 4 & 15 \\
Myocardial rupture & 4 & 8 \\
Stroke & 4 & 4 \\
Other & 4 & 8 \\
Time to death (days) & $(0,1,9)$ & $(2,4,14)$ \\
(25th, 50th, 75th percentile) & & \\
\hline
\end{tabular}

none of those with single-vessel disease $(p<0.01)$. The remote zone was hyperkinetic, on the other hand, in $50 \%$ of the latter group compared with $4.5 \%$ of those with multivessel disease $(p<0.005)$ In the canine model augmented function of the nonischemic myocardium during acute coronary occlusion has been reported by a number of investigators ${ }^{22-24}$ and has been attributed to a combination of the FrankStarling mechanism and regional unloading of the remote myocardium. Clearly, remote zone dysfunction and the presence of obstructive disease in the noninfarct vessels are intimately related variables. This is consistent with the observation that, in contrast to the study of Grines et al., ${ }^{y}$ in our study noninfarct zone function was not a significant independent predictor of mortality by multivariate analysis when the extent of coronary disease was forced into the regression equation.

Importance of coronary angiography. The findings of this study have important implications for the timing of diagnostic cardiac catheterization after myocardial infarction. Although one study ${ }^{25}$ has recently concluded that coronary angiography need not be performed in the absence of recurrent, spontaneous, 
Table V. Univariate predictors of in-hospital mortality $(\mathrm{n}=708)$

\begin{tabular}{lcc}
\hline & Chi-square & $p$ Value \\
\hline Clinical variables & & \\
Age (yr) & 15.5 & 0.0001 \\
Diabetes \pm hypertension & 9.2 & 0.002 \\
Sex & 5.3 & 0.02 \\
Systolic blood pressure & 4.0 & 0.04 \\
Heart rate & 3.3 & 0.07 \\
ECG location of infarction & 1.3 & 0.26 \\
Catheterization variables & & \\
Number of diseased vessels & 17.8 & $<0.0001$ \\
Left ventricular ejection fraction & 14.8 & 0.0001 \\
Noninfarct zone wall motion & 14.5 & 0.0001 \\
90-minute TIMI grade flow & 9.8 & 0.002 \\
Infarct zonte wall motion & 9.7 & 0.002 \\
Infarct-related artery & 3.0 & 0.39 \\
\hline
\end{tabular}

Table VI. Predictors of in-hospital mortality by stepwise logistic regression analysis $(n=708)$

\begin{tabular}{lrcc}
\hline \multicolumn{1}{c}{ Variable } & Beta & Chi-square & $p$ Value \\
\hline Number of diseased vessels & 0.600 & 9.26 & 0.002 \\
Left ventricular ejection fraction & -0.039 & 6.73 & 0.01 \\
Patient age (yr) & 0.039 & 4.68 & 0.03 \\
TIMI grade flow (90 min) & -0.740 & 4.54 & 0.03 \\
\hline
\end{tabular}

Constant $=0.763$

or exercise-induced myocardial ischemia, the ability of noninvasive functional testing to detect multivessel disease after thrombolytic therapy has not yet been validated. Exercise radionuclide ventriculography and thallium scintigraphy have shown relatively poor sensitivity for multivessel disease in patients treated conventionally. ${ }^{26,27}$ Although the sensitivity of resting and stress two-dimensional echocardiography appears to be somewhat better for the detection of multivessel disease, ${ }^{28}$ its predictive value after reperfusion therapy requires further evaluation. At the present time therefore coronary angiography remains the "gold standard" for the detection and evaluation of multivessel coronary artery disease.

Myocardial revascularization and short-term prognosis. The findings of this study also suggest that early definitive revascularization procedures may improve the short-term outlook for patients with multivessel coronary disease. The majority of the deaths in the group with multivessel disease were due to reinfarction or myocardial failure and occurred at a median of 4 days from the time of admission. The role of early coronary angioplasty after myocardial reperfusion has received a great deal of recent attention. Results of several studies ${ }^{29-31}$ have shown no improvement in short-term outcome for patients treated by immediate balloon angioplasty of the infarct-related artery after successful tissue plasminogen activator-mediated thrombolysis. Although double and triple-vessel coronary angioplasty has been reported to be feasible and safe when performed 1 to 2 weeks after acute myocardial infarction, ${ }^{32}$ it is likely that such intervention during the first few days after the index event would be associated with a high risk of major hemodynamic compromise in the event of acute closure of the noninfarct vessels. Very early coronary artery bypass graft surgery, on the other hand, may improve regional myocardial dysfunction in both the infarct and noninfarct territories and improve short-term survival. Randomized, controlled comparisons of emergency surgical revascularization for acute myocardial infarction with either coronary angioplasty or thrombolysis alone have not yet been reported. However, immediate and sustained improvement in regional myocardial function has been documented after elective surgical revascularization ${ }^{33}$ and in patients undergoing emergency coronary artery bypass graft surgery after thrombolytic therapy for acute infarction. ${ }^{34}$ The impact of acute surgical revascularization on the survival of patients with myocardial infarction complicated by cardiogenic shock remains unclear. Although the in-hospital mortality rate remains substantial in the surgically treated group, on the basis of several small observational studies, the short-term prognosis for patients with multivessel disease appears to be somewhat better than that for patients treated with conventional medical therapy or thrombolysis alone. ${ }^{35}$ Emergency coronary angioplasty of the infarct-related artery alone does not appear to provide adequate myocardial revascularization to improve the outlook for patients with multivessel disease and cardiogenic shock ${ }^{36,37}$ in whom noninfarct zone function remains compromised by hemodynamically significant noninfarct vessel stenoses. The efficacy of multivessel angioplasty in this setting has not been adequately investigated.

Conclusions. The strongest predictor of short-term prognosis after thrombolytic therapy for acute myocardial infarction in this large study was the presence of multivessel coronary artery disease. Until such time as noninvasive methods such as stress echocardiography or scintigraphy have been perfected and validated, early coronary angiography remains the diagnostic procedure of choice for detecting the presence of multivessel coronary artery disease and provides valuable prognostic information after acute myocardial infarction.

\section{REFERENCES}

1. Kennedy JW, Ritchie JL, Davis KB, et al. The Western Washington intravenous streptokinase in acute myocardial infarction randomized trial. Circulation 1988;77:345-52. 
2. The ISAM Study Group. A prospective trial of intravenous streptokinase in acute myocardial infarction (ISAM): mortality, morbidity, and infarct size at 21 days. N Engl J Med 1986;314:1465-71.

3. White HD, Norris RM, Brown MA, et al. Effect of intravenous streptokinase on left ventricular function and early survival after acute myocardial infarction. N Engl J Med 1987;317: 850-5.

4. Gruppo Italiano per lo studio dello streptochinasi nell 'infarto miocardico. Long-term effects of intravenous thrombolysis in acute myocardial infarction: final report on the GISSI study. Lancet 1987;2:871-4.

5. ISIS-2 Collaborative Group. Randomized trial of intravenous streptokinase, oral aspirin, both or neither among 17,187 cases of suspected acute myocardial infarction: ISIS-2. Lancet $1988 ; 2: 349-60$

6. Wilcox RG, Olsson CG, Skene AM, et al. for the ASSET Study Group. Trial of tissue plasminogen activator for mortality reduction in acute myocardial infarction. Anglo-Scandinavian Study of Early Thrombolysis (ASSET). Lancet 1988;2:525-30.

7. The Multicenter Postinfarction Research Group. Risk stratification and survival after myocardial infarction. $N$ Engl $J$ Med 1983;309:331-6.

8. Van de Werf F. Discrepancies between the effects of coronary reperfusion on survival and left ventricular function. Lancet $1989 ; 1: 1367-9$

9. Grines CL, 'Topol EJ, Califf RM, et al. Prognostic implications and predictors of enhanced regional wall motion of the noninfarct zone after thrombolysis and angioplasty therapy of acute myocardial infarction. Circulation 1989;80:245-53.

10. Topol EJ. An overview of the Thrombolysis and Angioplasty in acute Myocardial Infarction (TAMI) trials. Arch Mal Coeur 1988;81:45-9.

11. Sander H, Dodge HT. The use of single-plane angiocardiograms for the calculation of left ventricular volume in man. AM HEART J 1968;75:325-34.

12. Sheehan FH, Bolson EL, Dodge HT, Mathey DG, Schofer J, Woo HW. Advantages and applications of the centerline method for characterizing regional ventricular function. Circulation 1986;74:293-305.

13. Mancini GBJ, Simon SB, McGillem MJ, et al. Automated quantitative coronary angiography: morphologic and physiologic validation in vivo of a rapid digital angiographic method. Circulation 1987;75:452-60.

14. Mock MB, Ringqvist I, Fisher LD, et al. Survival of medically treated patients in the Coronary Artery Surgery Study (CASS) Registry. Circulation 1982;66:562-8.

15. Bruschke AVG, Proudfit WL, Sones FM. Progress study of 590 consecutive nonsurgical cases of coronary disease followed 5-9 years. I. Arteriographic correlations. Circulation 1973;47:1147. 53.

16. Taylor GJ, Humphries JO'N, Mellits ED, et al, Predictors of clinical course, coronary anatomy and left ventricular function after recovery from acute myocardial infarction. Circulation 1980;62:960-70.

17. Schulman SP, Achuff SC, Griffith LSC, et al. Prognostic car diac catheterization variables in survivors of acute myocardial infarction: a five year prospective study. J Am Coll Cardiol 1988;11:1164-72.

18. Jaarsma W, Visser CA, Eenige Van MJ, et al. Prognostic implications of regional hyperkinesia and remote asynergy of noninfarcted myocardium. Am J Cardiol 1986;58:394-8.

19. Schuster $E H$, Bulkley $B H$. Ischemia at a distance after acute myocardial infarction: a cause of early postinfarction angina. Circulation 1980;62:509-15.

20. Schuster EH, Bulkley BH. Early post-infarction angina. Ischemia at a distance and ischemia in the infarct zone. N Engl $J$ Med 1981;305:1101-5.
21. Stamm RB, Gibson RS, Bishop HL, Carabello BA, Beller GA, Martin RP. Echocardiographic detection of infarct-localized asynergy and remote asynergy during acute myocardial infarction: correlation with the extent of angiographic coronary disease. Circulation 1983;67:233-44.

22. Theroux P, Franklin D, Ross J, Kemper WS. Regional myocardial function during acute coronary artery occlusion and its modification by pharmacologic agents in the dog. Circ Res 1974;35:896-908.

23. Lew WYW, Chen Z, Guth B, Covell JW. Mechanisms of augmented segment shortening in noninschemic areas during acute ischemia of the canine left ventricle. Circ Res 1985;56: $351-8$.

24. Akaishi M, Schneider RM, Mercier RJ, Agarwal JB, Helfant $\mathrm{RH}$, Weintraub WS. Analysis of phases of contraction during graded acute myocardial ischemia. Am J Physiol 1986;250: H778-85.

25. The TIMI Study Group. Comparison of invasive and conservative strategies after treatment with intravenous tissue plasminogen activator in acute myocardial infarction. Results of the Thrombolysis in Myocardial Infarction (TIMI) phase II trial. N Engl J Med 1989;320:618-27.

26. Younis LT, Byers S, Shaw L, Barth G, Goodgold H, Chaitman $B R$. Prognostic value of intravenous dipyridamole thallium scintigraphy after an acute myocardial ischemic event. Am J Cardiol 1989;64:161-6.

27. DeBusk RF. Specialized testing after recent acute myocardial infarction. Ann Intern Med 1989;110:470-81

28. Jaarsma W, Visser CA, Kupper AJ, Res JC, van-Eenige MJ, Roos JP. Usefulness of two-dimensional exercise echocardiography shortly after myocardial infarction. Am $\mathrm{J}$ Cardiol 1986;57:86-90.

29. Topol EJ, Califf RM, George BS, et al. A randomized trial of immediate versus delayed elective angioplasty after intravenous tissue plasminogen activator in acute myocardial infarction. N Engl J Med 1987;581-8.

30. The TIMI Research Group. Immediate versus delayed catheterization and angioplasty following thrombolytic therapy for acute myocardial infarction. JAMA 1988;260:2849-58.

31. Simoons ML, Arnold AER, Betriu A, et al. Thrombolysis with tissue plasminogen activator in acute myocardial infarction: no additional benefit from immediate percutaneous coronary angioplasty. Lancet 1988;1:197-203.

32. Nath A, DiSciascio G, Vetrovec GW, et al. Double and triple vessel coronary angioplasty early after myocardial infarction; immediate results, long term follow-up [Abstract]. J Am Coll Cardiol 1990;15:75A.

33. Topol EJ, Weiss JL, Guzman PA, et al. Immediate improvement of dysfunctional myocardial segments after coronary revascularization: detection by intraoperative transesophageal echocardiography. J Am Coll Cardiol 1984;4:1123-34.

34. Kereiakes DJ, Topol EJ, George BS, et al. Emergency coronary artery bypass surgery preserves global and regional left ventricular function after intravenous tissue plasminogen activator therapy for acute myocardial infarction. J Am Coll Cardiol 1988;11:899-907.

35. Bolooki H. Emergency cardiac procedures in patients in cardiogenic shock due to complications of coronary artery disease. Circulation 1989;79(suppl 1):137-48.

36. Lee L, Bates ER, Pitt B, Walton JA, Laufer N, O'Neill WW. Percutaneous transluminal coronary angioplasty improves survival in acute myocardial infarction complicated by cardiogenic shock. Circulation 1988;78:1345-51.

37. Kahn JK, Rutherford BD, McConahay DR, et al. Primary angioplasty of acute myocardial infarction in patients with multivessel coronary artery disease [Abstract]. Circulation 1989;II625 . 